\title{
7 \\ Assessing the Personal: Inclusion, Anecdote, and Academic Writing
}

\author{
Linda Westphalen \\ University of Adelaide
}

In the School of Education at the University of Adelaide, the use of oral evidence is increasingly common as students engage with reflective practices now dominant in teacher-education programs. These experiences offer both a dynamic perspective and a challenge to academic assessors and raise three questions, each of which are addressed in this paper: How should one regard oral history or personal experience in an academic context? How does one assess an academic argument which uses oral evidence or personal experience? What does it mean to be culturally inclusive in one's teaching? This paper argues that academics must accept the disruptive challenge of alternative constructions of knowledge, including personal histories, if the notion of what it means to be culturally inclusive is to be more than a token.

\section{Introduction}

A $s$ academic institutions become increasingly inclusive of students from diverse backgrounds, the students' cultural and historical contexts form a dynamic scaffold upon which Western academic conventions of knowledge (whatever they are) are grafted. Yet, academic teachers in universities frequently have little understanding of the cultural and historical contexts of their students, thus endangering the viability of the 'graft.' Ironically, when students provide such contexts for their conceptual development, especially as a reflective practice in their assessed writing, the experience fragments presented are often un- assessed relative to other data. This is particularly so if the experiences are from a minority culture, such as Indigenous Australian - one significantly removed from the academic's own ontological view.

This paper addresses some of the issues concerning inclusive education and cultural difference, with particular regard to the use of oral history, personal experience, or anecdote in assessed essays. The paper takes its theoretical lead from the research of mathematics teacher-educator, Ron Tzur (2001), who contends that development occurs "via reflection on activities" and "the presentation and analysis 
of fragments of experience" (p. 260). In keeping with social constructivist models of learning, and drawing on the work of Dewey, Piaget, and Schön, Tzur considers that "reflection on one's actions and on those of others while interacting with people and objects in the environment... [is] the mental root of conceptual development" (p. 261). This contention, along with an almost axiomatic distrust of oral sources by academics, gives rise to important questions for teachers in universities, notably the following:

1. How should one regard oral history or personal experience in an academic context?

2. How does one assess an academic argument which uses oral evidence or personal experience?

3. What does it mean to be culturally inclusive in one's teaching?

\section{'Academic' Writing?}

Historically, writing has functioned to keep records more permanently and accessibly than in oral forms. Academic institutions have long asserted the primacy of the written over the oral, where the former is assumed to be objective, factual, and verifiable, and the latter is subjective, unreliable, and transient. Orally held knowledges, such as those pertaining to life histories, are often distrusted in academic discourses unless they can be supported by written evidence, while the absence of written records is understood to infer an absence of knowledge (e.g., Rose, 2001, p. 112-113).

An Indigenous student, for example, is thus confronted with a dilemma. If she records her experiences without supporting documentation, her oral histories and knowledges are suspect. If she does not record her experiences, she is considered an 'insider,' as having nothing significantly different in her experience to report. Either way, the dilemma materially disadvantages the student.

All evidence is experienced, whether constructed in academic contexts or not, oral or written, qualitative or quantitative. This contention goes to the very heart of education as it is theorised to operate, that is, as a subjective construction of knowledge based intimately on the prior knowledge and contemporary perspectives of the learner (Dewey, 1938; Piaget as cited in Dunn, 2005). Humans, thus, experience data at all levels of its formation, interpretation, and consumption: its conception as a primary source, its analysis relative to other sources, and its "ingestion" by readers, who actively reconstruct the data, cognitively and creatively making sense of what is seen or heard, relative to their own past and current contexts (Eagleton, 1996, p. 66-67).

In the development of meaning making, then, our engagement with data depends, to a large degree, on how it sits relative to other data, including our own experiences and memories. Jan Pettman (1992) proposes:

Meaning is constructed by position and relationship, rather than by what 'really' happened. This is not to say that memory is not true or accurate; rather that it is a reconstruction which speaks to where the person is now, and to the social setting within which that person now stands. (p. 142)

In an academic context, life history data should not be considered as particularly different from other data, especially given that, although written data has academic primacy, this does not necessarily equate with accuracy. Simply, just because something is written down, does not make it more 'true' than if it were articulated verbally. Academic endeavour in western universities is grounded in critique, yet oral sources, including personal histories, are not critiqued so much as ignored in tertiary learning, particularly in the non-social sciences and humanities. If academics (whether in departments of education or not) are to understand the cultural contexts of the students who attend their courses, and to effectively address the issue of the nexus between experience and constructions of learning, then this rejection needs to be reconsidered, especially with regard to assessment. 


\section{Assessing the Personal}

As Cooney and Krainer (1996) contend, "teacher education programs are becoming less technically oriented and more process or constructivist oriented with an emphasis on reflection and self analysis" (p. 1159). This provides a context for some assessed academic writing in teacher education courses in the School of Education at the University of Adelaide. Students reflect on their own experiences of education (primary, secondary, or tertiary), since these experiences have a kind of forward 'ripple' effect on the developing ontologies, core values, and pedagogies of people who aim to be teachers. Events in peoples' lives act as points around which evolving consciousnesses of what it means to teach and be taught recur.

Reflective practice is fundamental to education, but given the nexus between experience and learning outlined above, this practice is an educationwide phenomenon. Although essay questions have clearly required reflective elements in some courses, little provision has been made to unpack oral history or reflection relative to formal assessment criteria or matrices until recently.

Assessment has different purposes: for example, testing conceptual understanding and skills, the development of an argument, scaling a student relative to others, and so on. To reject a personal history because it has not been asked for in an essay question is, in some circumstances, justified. To not acknowledge it in an assessment when it has been explicitly asked for is ethically questionable. In either event, failure to give due recognition to a personal history undermines the student's cultural identity and perspectives, contributes to subjugation of (minority) knowledges and ongoing colonisation, and asserts a power regime beyond a teaching relationship. Materially, it disadvantages a (minority) student who has sometimes shared a significant and/or personally confronting event with a lecturer.

It also suggests that experiences in the past have no political, social, or historical context at the time of the event, and no connection with the present subjectivity of the student. While direct experience allows the connection between the personal and the political (in keeping with the long held feminist axiom), the personal is also the historical and/or the counter-historical, since the autobiographical element also offers what, for the author/narrator at least, is a self-evident and authentic event, which can present a dynamic challenge to "mainstream" discourses (Longley, 1997, p. 213), a space where the university routinely functions.

Given these considerations, assessing the personal histories in essays is as important as assessing other elements, such as the argument or the conceptual comprehension. First, though, the whole educational 'package' provided for the student, in whatever subject area, must contend with the social construction of learning outlined in the first section of this paper. Subject curriculum writers must set learning outcomes that address the cultural and historical contexts of students, not just because all students' learning will be enhanced, but because inclusive practice demands that we understand our students and consider their learning needs culturally, especially with regard to those students who occupy spaces of difference.

Second, if academics ask for reflective practices, such as the integration of oral/experiential evidence in an academic essay, then the process of integration needs to be explicitly taught. This teaching can happen relative to assessment criteria, and these should show a clear distinction between poor and good integration of oral evidence with other data. The oral evidence also needs to be considered relative to other aspects of the overall assessment. A marking matrix is included as an example (Table 1).

A key consideration in the assessment matrix is the idea that personal history, anecdote, or oral evidence should not just be presented, but that it should be both synthesised with other arguments and analysed. In other words, the student must make the personal history meaningful within the context of the essay and relative to other arguments presented. However, while this analysis could involve critique of the personal history, this should not be expected of the student, nor should $s$ /he be penalised for failing to critique his/her own experiences. Depending on the context, critique could be construed as a requirement to self-depreciate or undermine a cultural practice or identity, all of which are counter to inclusive practice. 


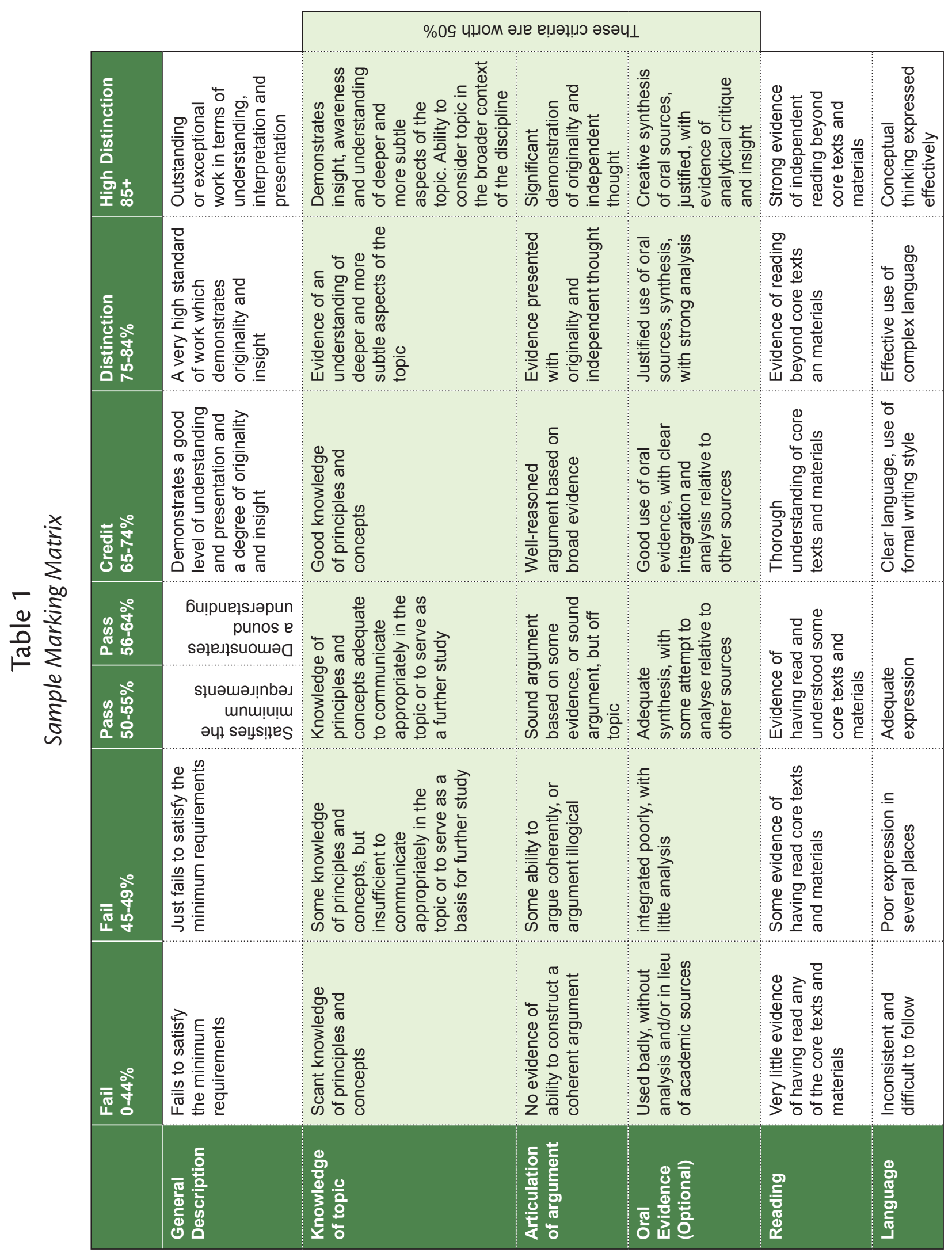




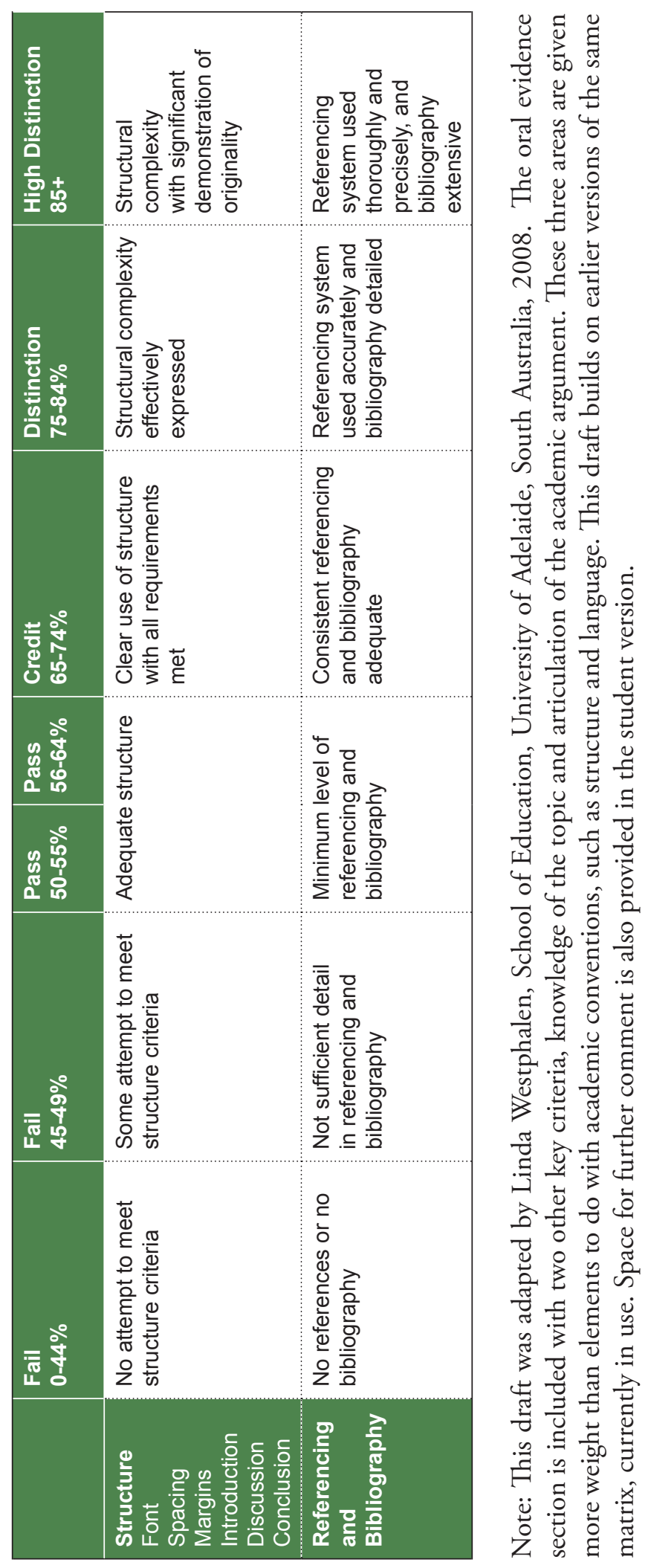




\section{Inclusive Cultures}

Graham and Slee (2007) contend that "authentically inclusive education invites the denaturalisation of 'normalcy' to arrive at a ground zero point from which we banish idealisations of centre" (p. 280). They continue by arguing that, "although predicated as natural and true, the rule of the norm is statistically derived, negating the diversity to be found within nature and the naturalness of diversity" (p. 281). In other words, inclusive practice includes, ironically, reflecting on and critiquing the mythic centre or "norm" (however this is constructed) which can withhold access to students constructed as Other relative to itself. In addition, while minorities exist and are marginalised, a lecturer can never be certain just where diversity will challenge the assumed paradigmatic "norm" of the "centre." Students do not necessarily wear their difference (however this is constructed) overtly. This, in addition to the fact that the issue of inclusion and anecdotal evidence can affect any student, is why the word 'minority' is bracketed above.

Longley (1997), referring to "multicultural writing," asserts:

$[\mathrm{F}]$ amily histories are providing new historical information in the form of recorded memories, which have in the past been considered irrelevant or peripheral to Australia's national self-image...they are actively changing public understanding of the nature of the genre of national history in terms of its conventions, its ideologies and its principles of selection...Family history as micro-history provides an ongoing and cumulative challenge to the authority of established forms of macro-history. (p. 213)

This challenge to the "authority of established forms of macro-history" should be extended to include the authority of the institution of the academy itself.

The role of education has been long debated by theorists (Austin, 2007, p. 8-24). While university researchers usually see themselves at the forefront of critical pedagogies, aiming to positively transform the lives of humans, particularly the marginalised and disadvantaged, how far they are able to reflect on the exclusionary tactics and barriers in their own teaching, and about the institutions which locate and (often) fund their research, is unknown. Additionally, to elicit change within the university - to alter the very paradigms which valorise 'white' western institutions and constructions of knowledge - is not easy, especially by members of a privileged community whose interests are served by maintaining a status quo. Students are in an unbalanced power relationship relative to academics: those who challenge academic authority take a very big risk indeed.

In Australian universities, there is recognition of the need to address the cultural diversity of students in course offerings (see University of Adelaide, 2008); however, there is a great deal of mileage between understanding cultural diversity and implementing inclusive policies, some of which will undermine the fabric of universities themselves. When a student reports that they have been admonished for speaking 'like an Asian' in a bridging program designed to assist international students in integrating in an Australian university, this gap becomes (among other things) just plain embarrassing.

Cultural diversities need to be understood in terms of power, hegemony, diasporas, hybridity, gender, sexualities, and differences in abilities. Inclusive practices involve relating all of these things to academic subject areas and professions and accepting that universities, as depositories of knowledge, represent the privileged and selective epistemologies and ontologies of the people in power. Anthropologist Deborah Bird Rose (1999) suggests that Western thought and action is "dominated by a matrix of hierarchical oppositions which provides powerful conceptual tools for the reproduction of oppression" (p. 176). She argues that:

A critical feature of this system is that the 'other' never gets to talk back on its own terms. The communication is all one way, and the pole of power refuses to receive the feedback that would cause it the change itself, or to open itself to dialogue. Power lies in the ability not to hear what is being said... The self sets itself with a hall of mir- 
rors; it mistakes its reflection for the world, sees its own reflections endlessly, talks endlessly to itself and, not surprisingly, finds continual verification of itself and its world view. ... [I]t is narcissism so profound that it purports to provide a universal knowledge when in fact its violent erasures are universalizing its own singular and powerful isolation [sic]. (p. 176-177)

If critical pedagogies are to be maintained as realities in our tertiary education systems, if inclusion is to be realised, and if these are both to transfer to the workspaces of our graduates, then engaging with the chaotic multiple subjectivities who are our students in meaningfully dialogic ways is an essential process.

\section{Conclusion}

This paper has explored the inclusion and assessment of personal histories, as part of reflective practice and in acknowledgment of increasingly culturally diverse university communities. Understanding how differences can manifest themselves in the teaching-learning relationship is important. Instead of dismissing personal experiences on which new knowledges are grafted, academic teachers need to embrace the contexts students provide, however unruly and challenging, so as to meaningfully engage with inclusive practices.

\section{References}

Austin, J. (2007). Education and social change. In J. Austin \& A. Hickey (Eds.), Education for healthy communities: Possibilities through SOSE and HPE (pp. 8-24). Frenchs Forest: Pearson Education Australia.

Cooney, T.J. \& Krainer, K. (1996). Inservice mathematics teacher education: The importance of listening. In A.J. Bishop, K. Clements, C. Keitel, J. Kilpatrick, \& C. Laborde (Eds.), International handbook of mathematics education (pp. 1155-1185). London: Kluwer.
Dewey, J. (1938). Experience and education. London: Collier-Macmillan.

Dunn, S. (2005). Philosophical foundations of education: Connecting philosophy to theory and practice. Upper Saddle River: Pearson.

Eagleton, T. (1996). Literary theory: An introduction. Oxford: Blackwell.

Graham, L. \& Slee, R. (2007). An illusory interiority: Interrogating the discourse/s of inclusion. Educational Philosophy and Theory, 40(2), 277-293.

Longley, K. (1997). Little histories: Diasporan family narratives in Australia. Southern Review, $30(2), 212-225$.

Pettman, J. (1992). Living in the margins: Racism, sexism and feminism in Australia. St Leonards: Allen and Unwin.

Rose, D.B. (1999). Indigenous ecologies and an ethic of connection. In N. Low (Ed.), Global ethics and environment (pp. 175-187). London: Routledge.

Rose, D.B. (2001). The silence and power of women. In P. Brock (Ed.), Words and silences: Aboriginal women, politics and land (pp. 92-116). Crows Nest: Allen and Unwin.

Tzur, R. (2001). Becoming a mathematics teachereducator: Conceptualizing the terrain through self-reflective analysis. Journal of Mathematics Teacher Education, 4, 259-283.

University of Adelaide. (2008). Building a great research university: The University of Adelaide strategic plan 2008-2012. Retrieved September 25, 2008 from http://www.adelaide.edu.au/ $\mathrm{VCO} /$ strategicplan/Strategic\%20Plan\%20 2008-2012\%20(amended\%20070408).pdf 


\section{Biography}

Linda Westphalen is a lecturer in Cultural Studies in the School of Education at the University of Adelaide, South Australia. Her teaching and research interests focus on Cultural Studies issues to do with education, ICT, Media, and Higher Degree supervision. Her interests also include Gifted Education, Memory Work, and gender debates. 